\title{
Corona Lockdown to Locked in Syndrome: A Neurosurgeon's Perspective
}

\author{
Samir K. Kalra ${ }^{1}$ Vandana Kalra ${ }^{2}$ Raj Kumar ${ }^{3}$ \\ ${ }^{1}$ Department of Neurosurgery, Sir Ganga Ram Hospital and \\ Ganga Ram Insitute of Medical Education and Research, \\ New Delhi, India \\ 2Department of Radiology, Delhi Heart and Lung Institute, \\ New Delhi, India \\ ${ }^{3}$ Department of neurology, Uttar Pradesh University of Medical \\ Sciences, Etawah, Uttar Pradesh, India \\ Indian J Neurosurg:2020;9:186-187
}

\begin{abstract}
Address for correspondence Raj Kumar, MS, MCh, PhD, DSc, FRCS, FAMS, FNS, FASET, MRCS, MNASc, Uttar Pradesh University of Medical Sciences, Saifai, Etawah, Uttar Pradesh 206130, India (e-mail:vc@upums.ac.in, rajkumar1959@gmail.com).
\end{abstract}

\author{
Abstract \\ Keywords \\ - COVID-19 \\ - lockdown \\ - locked in syndrome
}

We are spending our days today in a nationwide lockdown. The government should be lauded for taking a firm stand and announcing this lockdown well in time. Perhaps the benefits of social distancing cannot be more emphasized to prevent the spread of the dreaded coronavirus as witnessed by some of the developed nations who missed out by announcing it very late. In this lockdown period when we are primarily confined to our home, people face this dilemma of what to do and what lies ahead. Suddenly people find themselves in a situation where they are forced to stay at home and there is fear and turmoil all around. The mindset in this situation quickly becomes negative and as is well known "empty mind is devil's workshop." The need of the hour is to get constructively active and keep the positive vibes going.
In neurosurgical parlance, a syndrome described as locked in syndrome is well known. ${ }^{1}$ This is caused mostly by ventral pontine lesions due to bilateral interruption of corticospinal and corticobulbar tracts. This leads to disruption of voluntary control of limb muscles and medullary motor nuclei. The patient is locked in and there is no voluntary movement of any of the four limbs, as well as no speech. However, since the tegmentum of pons is spared, vertical eye movements and blinking are preserved. The consciousness and cognition too are intact, as their centers of control are above pons ( - Fig. $\mathbf{1}$ ).

The affected person is aware of the surroundings; he can see and hear, understand, and communicate with eye movements. The treatment for this is primarily supportive and involves multidisciplinary approach. There have been instances of few people having been in this locked in state but have been so very positive in adversity and were able to make extremely notable contributions. ${ }^{1,2}$ Gary Parkinson, a professional footballer is one such example. He went into this state following brain stroke.
He, however, pursued with his career by continuing to be a part of Middlesbrough football club (FC)'s scout analysis team where he would watch potential players on DVD relaying his inputs through blinking. Noteworthy also is the example of Stephen Hawking, a noted English theoretical Physicist and author who is said to have been in this state and still contributed by communicating using his eyes and cheek muscles movements. He was the Lucasian Professor of Mathematics, described the Hawking radiation, and is said to have supervised 39 successful $\mathrm{PhD}$ students despite his disabilities. Martin Pistorius is another known patient who worked as freelance web designer/developer and published a book about his life, namely, Gost Boy. They are a few examples of people who had shown so much exemplary courage and positivity that they could contribute even in the most trying times. ${ }^{1,2}$ To take a leaf out of their book, we need to understand that the lockdown is an opportunity to do something positive and constructive. It is hence a time when we must stop thinking
DOI https://doi.org/ $10.1055 / \mathrm{s}-0040-1712185$ ISSN 2277-954X. (c) 2020. Neurological Surgeons' Society of India.

This is an open access article published by Thieme under the terms of the Creative Commons Attribution-NonDerivative-NonCommercial-License, permitting copying and reproduction so long as the original work is given appropriate credit. Contents may not be used for commercial purposes, or adapted, remixed, transformed or built upon. (https://creativecommons.org/licenses/by-nc-nd/4.0/)

Thieme Medical and Scientific Publishers Pvt. Ltd., A-12, 2nd Floor, Sector 2, Noida-201301 UP, India 


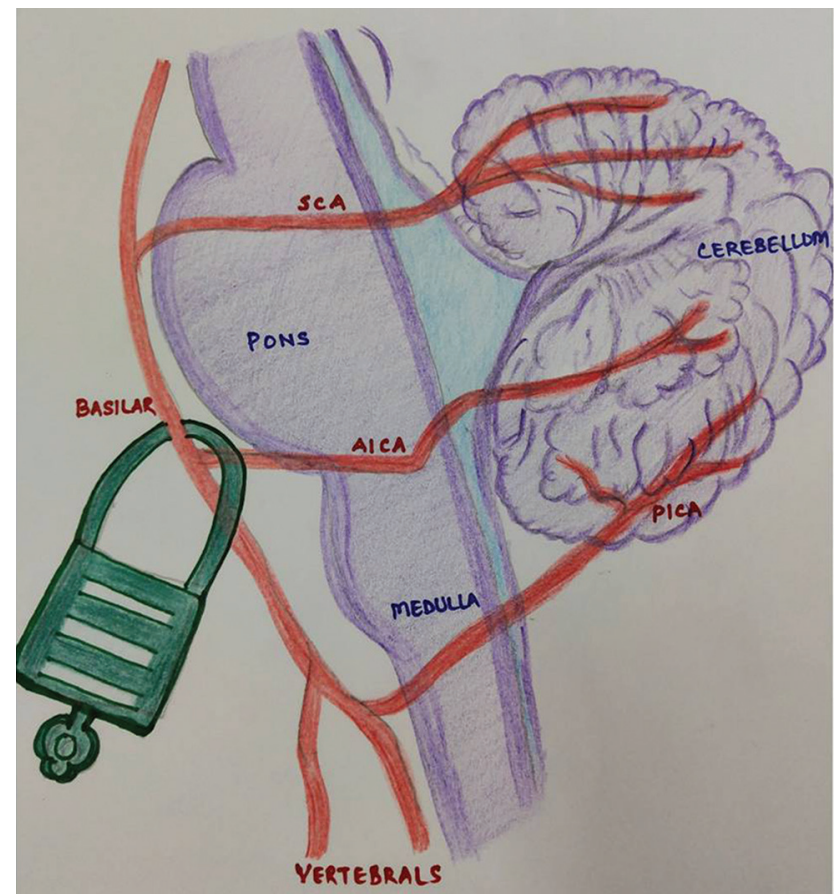

Fig. 1 An illustration to locked in syndrome. negative and start rediscovering ourselves, our hobbies, and our priorities which were so far lost in our day-to-day rigmarole of continuous duty. Let us rediscover empathy, compassion for all creations of the almighty. Let us not trudge into nature lest nature trudges upon us with all its might. Let us come out of it as better human beings than before and not just get locked in by this lockdown state.

\section{Conflict of Interest}

None declared.

\section{Acknowledgment}

The authors would like to acknowledge the almighty for giving this opportunity to educate and motivate the people during this crisis.

\section{References}

1 Bauer G, Gerstenbrand F, Rumpl E. Varieties of the locked-in syndrome. J Neurol 1979;221(2):77-91

2 Laureys S, Pellas F, Van Eeckhout P, et al. The locked-in syndrome: what is it like to be conscious but paralyzed and voiceless? Prog Brain Res 2005;150:495-511 